\title{
PhenOtYPing ARCHITECTURE TRAits OF TREE SPECIES USING REMOTE SENSING TECHNIQUES
}

\author{
Worasit Sangjan $^{1}$, Sindhuja Sankaran ${ }^{1, *}$ \\ ${ }^{1}$ Department of Biological Systems Engineering, Washington State University, Pullman, Washington, USA. \\ * Correspondence: sindhuja.sankaran@wsu.edu.
}

\section{HighLIGHTS}

- Tree canopy architecture traits are associated with its productivity and management.

- Understanding these traits is important for both precision agriculture and phenomics applications.

- Remote sensing platforms (satellite, UAV, etc.) and multiple approaches (SfM, LiDAR) have been used to assess these traits.

- 3D reconstruction of tree canopies allows the measurement of tree height, crown area, and canopy volume.

\begin{abstract}
Tree canopy architecture is associated with light use efficiency and thus productivity. Given the modern training systems in orchard tree fruit systems, modification of tree architecture is becoming important for easier management of crops (e.g., pruning, thinning, chemical application, harvesting, etc.) while maintaining fruit quality and quantity. Similarly, in forest environments, architecture can influence the competitiveness and balance between tree species in the ecosystem. This article reviews the literature related to sensing approaches used for assessing architecture traits and the factors that influence such evaluation processes. Digital imagery integrated with structure from motion analysis and both terrestrial and aerial light detection and ranging (LiDAR) systems have been commonly used. In addition, satellite imagery and other techniques have been explored. Some of the major findings and some critical considerations for such measurement methods are summarized here.
\end{abstract}

Keywords. Canopy volume, LiDAR system, Structure from motion, Tree height, UAV.

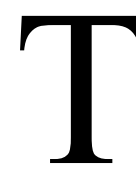

ree canopy architecture is a key aspect of crop productivity that affects light use efficiency, including light capture, light distribution, and biomass partitioning within the canopy. In orchard systems, primary aspects such as the support system, tree organization, planting density, and choice of rootstock and cultivars, along with annual operations associated with training systems such as pruning, training, and thinning, contribute to the canopy productivity (Costes et al., 2006). Similarly, in forest environments, diversity of the tree architecture contributes to variability in adult stature and horizontal light gradient, defining the forest ecosystem's growth rate and overall health (Sterck et al., 2001; Poorter et al., 2006). Thus, evaluation and phenotyping of tree architecture traits are essential for both precision agriculture and breeding applications. In precision agriculture, the growth and development of the canopy architecture determine the management decisions, such as the application of water and chemicals (nutrients, pesticides, etc.) and other operations (thinning, pruning, etc.). Application of chemicals with respect to changes

Submitted for review on 30 November 2020 as manuscript number MS 14419; approved for publication as an Invited Review Article and as part of the UAVs in Agriculture Collection by the Machinery Systems Community of ASABE on 2 August 2021. in the canopy architecture can reduce the use of chemicals by $30 \%$ to $45 \%$ (Miranda-Fuentes et al., 2016; Garcerá et al., 2017; Campos et al., 2019), thereby reducing negative impacts on the environment and promoting sustainability. Similarly, pre- and post-pruning analysis can be performed through evaluations of the canopy architecture (JiménezBrenes et al., 2017; Johansen et al., 2018).

For crop improvement and breeding programs in tree species, phenotyping of the canopy architecture is critical as it defines the light interception efficiency (Wu et al., 1994; Coupel-Ledru et al., 2019). Architectural plasticity is also known to contribute to genetic, ontogenetic, and environmental effects in apples (Segura et al., 2008, 2009). Fazio and Robinson (2008) reported that tree architecture traits, such as the number and angle of feathers in rootstock breeding, influence vigor and productivity. Kenis and Keulemans (2007) reported that genetic control of tree architecture could be dominated by environmental factors, highlighting the importance of tree architecture evaluation in breeding programs. Overall, tree architecture can affect the performance of different tree varieties with respect to their training system. The tree architecture affects growth and development, light interception and photosynthesis, and crop yield and fruit quality (Zhang et al., 2021). Given the development of new training systems, tree architecture (growth pattern and 
size) needs to be evaluated because it influences production and management practices, such as tree spacing, training, and pruning protocols, that are significantly related to production costs and yield (Caruso et al., 2015; Gokavi et al., 2021). In addition, uniformity of tree architecture traits is vital for high and stable yields in commercial production (López-Granados et al., 2019).

Based on the importance of phenotyping tree architecture traits for both precision management and crop breeding applications, this article discusses different sensing techniques and evaluated traits associated with the architectural characteristics of tree species. Both fruit and forest tree species are considered as the techniques that are applicable to one type are transferable to the other. Rosell and Sanz (2012) reviewed different sensing techniques and their applications in the extraction of geometric traits in tree crops, including stereo vision, ultrasonic, and light detection and ranging (LiDAR) systems. This article summarizes more recent literature and applications, many using the unmanned aerial vehicle (UAV) based approaches. We also discuss some crucial perspectives and future developments in this area.

\section{Sensor-BASED TeCHNIQUES \\ 3D Data Generating TeChNiQUes}

The 3D image processing techniques are vital for reconstructing 3D structure from the raw data before extracting targeted crop features. However, one of the significant factors for the process is the quality of the input data (Wang et al., 2020). For 3D data collection, optical systems built on three basic principles for depth measurement, i.e., triangulation, time of flight ( $\mathrm{ToF})$, and interferometry, are preferred over other techniques, such as sound detection and ranging (SONAR) and radio detection and ranging (RADAR), due to faster 3D acquisition, higher lateral resolution, safety, and common operating systems (Schwarte et al., 1999; Büttgen et al., 2005; Vázquez-Arellano et al., 2016; Iglhaut et al., 2019). Triangulation and ToF are the most commonly applied principles for generating 3D point clouds to estimate tree architecture traits.

\section{$3 D$ Construction Using Triangulation}

For the triangulation approach, the object's distance can be measured by knowing the triangle's angles or baseline, which is the most frequently used principle for depth measurement. In recent years, with the availability of high spatial resolution imagery, object-based image analysis (OBIA), in which image objects are characterized instead of individual pixel-based analysis, has become more commonly used (Hossain and Chen, 2019). The OBIA approach offers increased monitoring and mapping speeds (Fallati et al., 2020) and can be used to study shape, size, patterns, etc. (Blaschke, 2010). The OBIA approach can be applied to a 3D digital surface model (DSM) generated from UAV data using the structure from motion (SfM) principle. The DSM incorporates topographic information on both the canopy and the background within the region of interest. Next, a digital terrain model (DTM) is generated by creating the background or ground topographic layer from the DSM. Finally, a crop surface model (CSM), also referred to as a canopy height model (CHM), is computed by subtracting the DTM from the DSM.

In a recent study, de Castro et al. (2019) used an off-theshelf color camera without an infrared filter, which was mounted on an UAV to assess olive tree traits in large-scale phenotyping studies under field conditions. The point cloud $\left(\sim 4,500\right.$ points $\left.\mathrm{m}^{-2}\right)$ was generated using the SfM technique and was applied to create a DTM for the quantification of tree architecture traits. The results showed $\mathrm{R}^{2}$ values of 0.79 to 0.80 for tree height, 0.63 to 0.80 for tree area, and 0.50 to 0.79 for tree volume between measured (manual) and estimated traits at 27 months after planting. The estimates were more accurate for the hedgerow training system than for the intensive training system. The results also showed that the growth pattern (architectural training of olive trees such as tree size and age) had a significant effect on the underestimation of tree height, with normalized root mean square errors (RMSE) of $24.94 \%$ and $5.81 \%$ for 15 and 27 months after planting, respectively, for the hedgerow system. The researchers also reported that the accuracy of the DTM was directly affected by the point cloud density, which influenced the values of the estimated digital traits. A similar approach to estimating individual olive tree height was conducted by Díaz-Varela et al. (2015) using a modified RGB camera mounted on an UAV. In that study, the DSM generated by the SfM technique was used as the input to extract the tree height based on the identification of local maxima. The estimation results showed that the relative RMSE of height ranged from $6.55 \%$ to $19.24 \%$, and the errors depended on the architecture type and tree age.

Jurado et al. (2020b) assessed the impact of canopy reflectance based on the $3 \mathrm{D}$ tree structure of an individual treelevel forest inventory. Structural and spectral traits were extracted from images acquired using UAV-mounted RGB and multispectral cameras oriented at inclinations of $60^{\circ}$ (for better $3 \mathrm{D}$ model reconstruction) and $90^{\circ}$ (for accurate canopy reflectance measurement) relative to the ground. SfM photogrammetry was applied to construct a dense point cloud from the high-resolution RGB images with a ground sampling distance (GSD) of $1.09 \mathrm{~cm}$. Three vital factors were described in that study and in another study (Iglhaut et al., 2019) for achieving high-quality 3D tree models in forestry using the SfM technique: (1) the targeted traits need to be found in a minimum of three images, (2) the region of interest needs to have sufficient light intensity, and (3) the image scale may be reduced to $1 / 2$ or $1 / 4$ to promote identification of more critical or common points between overlapping images. The fusion method to map the multispectral images on $3 \mathrm{D}$ point clouds to create the geometry with spectral features (tree height, diameter at breast height, crown volume) was used to study the vegetation's physiological properties. Individual tree segmentation based on point clouds focused on the recognition of individual tree crowns and trunks. Extraction of tree morphology traits (using green, red, near-infrared, red edge, and normalized difference vegetation index) was performed on each tree. The study reported that higher reflectance in the near-infrared and strong absorption in the visible range was found in trees with higher crown volume and height. 
Johansen et al. (2018) evaluated the differences in lychee tree structure parameters before and after pruning by analyzing multispectral UAV imagery acquired at three UAV flight altitudes $(30,50$, and $70 \mathrm{~m})$. DSM and DTM were constructed using the SfM technique. In the study, CHM and orthomosaic spectral images were used to outline the individual tree crowns. Each tree's 90th percentile height, crown width, and crown perimeter were extracted and correlated with field measurements, which showed a lower RMSE at $30 \mathrm{~m}$ flying altitude than at the other altitudes. The study reported that the flight altitude influenced the geometry scale and size of the targeted region, thereby influencing the reconstruction quality and accuracy of the 3D model. MesasCarrascosa et al. (2020) acquired aerial images from UAV equipped with an RGB camera and combined 3D shape information with RGB spectral information for estimating the heights of individual grapevines. The autonomous program was implemented using color vegetation indices in point clouds to detect and classify points representing vegetation to measure the vine height with respect to the points classified as soil. The results showed $\mathrm{R}^{2}$ values greater than 0.87 and RMSE of $0.07 \mathrm{~m}$ between the actual and estimated crop heights, and the model was reported to be slightly more accurate $\left(\mathrm{R}^{2}=0.80, \mathrm{RMSE}=0.17 \mathrm{~m}\right)$ compared with the height estimation in a previous study applying raster vegetation height models (Caruso et al., 2017; de Castro et al., 2018; Pádua et al., 2018).

Dong et al. (2020) used an RGB-D camera, i.e., a stereo camera that provides color images with depth information, to evaluate apple tree structures. The study presented a novel technique to merge two sides (front and back) of the tree row for the reconstructed 3D model. Each side of the 3D model was generated from a combination of simultaneous localization and mapping (SLAM) and the SfM technique. The 3D model was generated using a coherent model by matching and merging features such as occlusion boundaries from orthographic views, trunks of the trees, and local ground. A shrink-and-expand algorithm to separate the trees and the alpha radius method to create the shape to enclose all 3D points of each segmented apple tree were implemented before computing each tree's traits, such as canopy volume, trunk diameter, and height. Merging of the two-sides reconstructions of the apple tree rows demonstrated improved tree height and trunk diameter accuracies compared with a onesided 3D model. Average estimation errors of the height and diameter were 3.80 and $0.49 \mathrm{~cm}$ for two sides, 5.90 and 0.54 $\mathrm{cm}$ for the front side, and 5.20 and $0.59 \mathrm{~cm}$ for the backside, respectively.

Similarly, Patrick and Li (2017) used an RGB camera (12 MP resolution) mounted on UAV platform to measure morphological characteristics such as bush height, extents, canopy area, volume, crown diameter, and width of highbush blueberry. The specific route for capturing the tree row images by flying over and next to (front and back) the targeted tree row and two flying altitudes $(4$ and $3 \mathrm{~m})$ with $90^{\circ}$ and $45^{\circ}$ angles of the camera to the row, respectively, were set to maximize the angles to cover the bush canopy and crown. The minimum flight speed was set at $0.4 \mathrm{~m} \mathrm{~s}^{-1}$ to optimize motion blur and receive more images for sufficient overlap for the SfM technique to create dense 3D point clouds of high quality. The study reported some errors in point cloud generation resulting from a breeze during data collection. The highest $z$-coordinate in the point cloud was extracted as the bush height; nevertheless, a trend of underestimation (shorter height) compared to manual measurements was found because of the effect of the camera's resolution.

UAV imagery (UAV integrated with RGB and a multispectral sensor) has gained extensive attention for mapping canopy and crown heights in forest and orchard environments, and SfM photogrammetry has become the primary 3D image generation technique. However, UAV imagery tends to underestimate the canopy height compared to field measurement data (Panagiotidis et al., 2017; de Castro et al., 2019; Krause et al., 2019). Krause et al. (2019) reported that a CHM of Scots pine measured from UAV-based data had similar accuracy to field-measured tree height, but there was also a tendency of underestimation when compared with ground reference data. A recommended solution to the issue of underestimation was using a correction factor that involved the leaning angle of a tree. This correction factor can be derived by estimating the planar distance of the treetop to the stem position and tree height.

\section{Time of Flight Sensor-Based Data}

In sensors that operate based on the time-of-flight principle, the sensors measure depth using the speed of light and the flight time, either directly or indirectly. LiDAR is one type of ToF sensor (fig. 1) and is generally preferred for tree characterization and reconstruction due to its high spatial resolution, higher throughput, and better canopy penetration. Wang et al. (2019) observed tree height in a Scandinavian boreal forest using the laser scan (LS) technique, referred to as topographical LiDAR, using airborne laser scanning (ALS) and terrestrial laser scanning (TLS) systems. Their results revealed that the ALS system's tree height measurements were more reliable and robust across tall tree stand conditions, and the ALS data provided accurate crown top height estimates regardless of tree height, crown shape, and species. The study suggested that high-density ALS data could be suitable for large-scale tree height surveys in the forest industry. One of the challenges was the omission of trees from the data acquired using the ALS system due to occlusion, which compromised the estimation of individual tree heights, especially trees from intermediate and suppressed classes (located next to larger trees whose crowns were partly or totally covered).

Colaço et al. (2017) applied a mobile TLS system with 2D LiDAR data to estimate the canopy volume and height of commercial orange trees. The 3D point clouds of the orange tree rows were created by combining the polar coordinates from the sensor and the vehicle movement along the orchard alleys. Two types of 3D modeling (convex hull and alpha shape) were used to reproduce the tree crown shape, and the researchers reported that the volume and height estimated from both reconstruction models were similar. Nevertheless, the study suggested that the convex hull method provided better results when handling transversal sections of the row, but the alpha shape method was a suitable alternative to represent specific orange trees. 


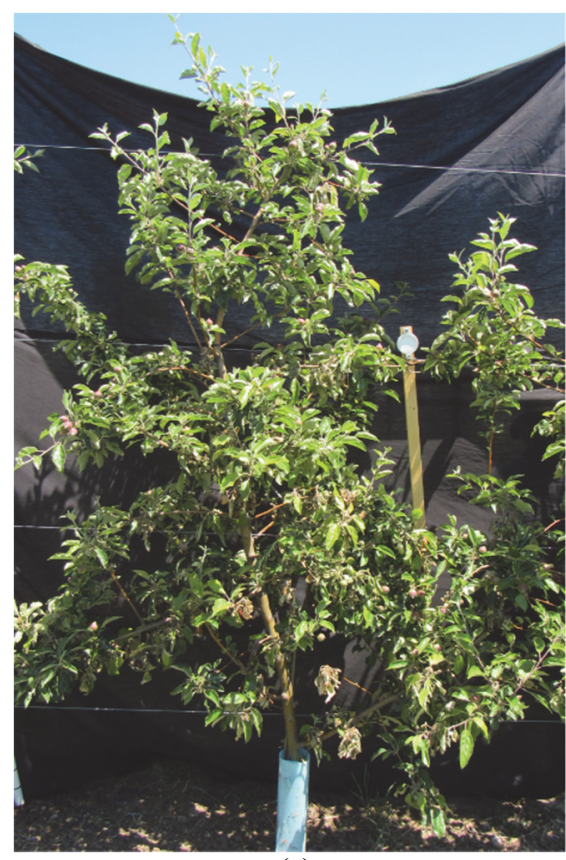

(a)

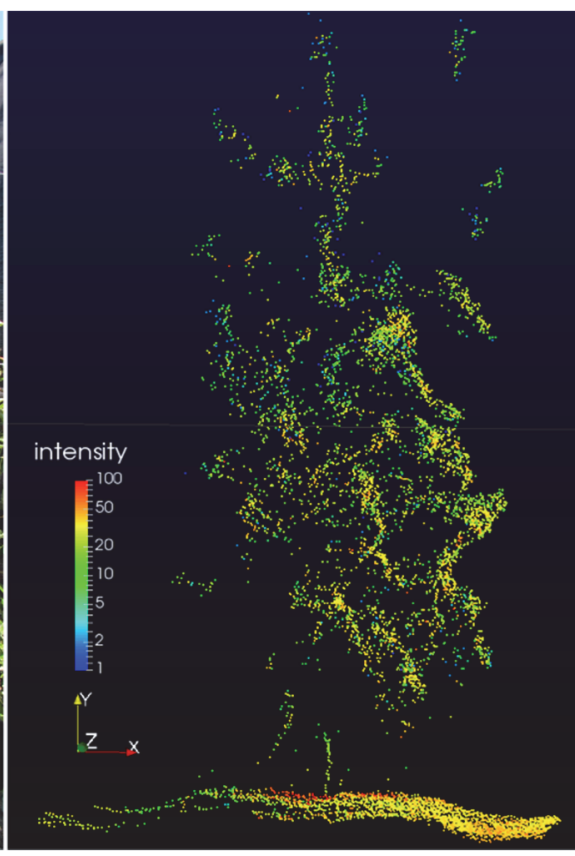

(b)

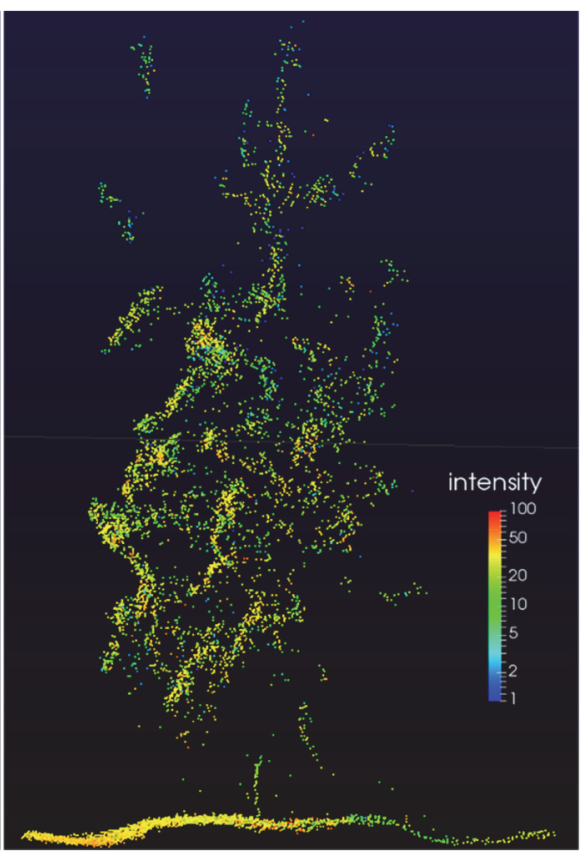

(c)

Figure 1. (a) Apple tree image acquired using RGB camera and (b, c) corresponding point cloud images generated using 3D LiDAR data acquired from different perspectives.

Camarretta et al. (2020) used UAV-LiDAR to extract traditional forest traits of individual eucalyptus trees, and several tree productivity and architecture traits (about 25) were assessed to filter for genetic signal differentiation between and within species. The tree height data were counted as one of the key structural differences between the two species of eucalyptus trees. In addition, traits such as crown density and structural complexity were found to be associated with the genetic diversity within and between species. Wu et al. (2020a) evaluated the ability of ALS and TLS data to assess the crown structure traits of individual fruit trees, including avocado trees, macadamia trees, and mango trees. Their study showed that ALS and TLS both provided similar crown area, fractional cover, and maximum crown height $\left(\mathrm{R}^{2} \geq 0.94\right.$, relative $\mathrm{RMSE} \geq 4.47 \%$ ), while the crown volume estimations were less correlated $\left(R^{2}=0.81\right.$, relative RMSE $=42.66 \%$ ), with the ALS approach underestimating such data compared to the TLS data, primarily due to the limited capacity of ALS data to measure lower branches and the within-canopy structure. The study reported that misclassified ground points, low point density, and misidentified crown apex might affect crown height underestimation using ALS data for the tree crops. Nonetheless, the ALS data were suitable for measuring the maximum crown height of horticultural trees of various ages, canopy patterns, height, and tree species.

Li et al. (2019) demonstrated a comparison of CHM in 3D forest mapping accuracy between a low-cost UAV-LiDAR system (DJI M600 Pro UAV with a Velodyne Puck VLP-16) and a standard UAV-LiDAR system (Hexa-rotor UAV with a Riegl VUX-1 laser scanner) during forest surveying. The CHM from the low-cost system showed comparable accuracies $\left(\mathrm{R}^{2}=0.998\right.$, $\left.\mathrm{RMSE}=0.32 \mathrm{~m}\right)$ to the standard system. Similarly, good results were obtained for tree crown diameter estimation $\left(\mathrm{R}^{2}=0.806, \mathrm{RMSE}=0.19 \mathrm{~m}\right)$ after excluding outliers. The researchers reported that the UAV integrated with the Velodyne scanner, which provided lower point density, was unsuitable for estimating low and complex structure trees. Hadas et al. (2017) compared tree height (average error $=19 \%$ ), crown base height (average error $=53 \%$ ), length of the longer diameter (average error $=$ $13 \%$ ), and perpendicular diameter (average error $=9 \%$ ) of 25 olive trees acquired from ALS data to field measurement data. In their study, an automated pipeline to estimate the tree traits was developed by applying the alpha shape algorithm to reconstruct the 3D model combined with principal component analysis (PCA) to find a suitable alpha $(\alpha)$ parameter.

Estornell et al. (2017) reported the estimation of crown structure parameters for walnut trees using TLS data to derive canopy volume, diameter, and height. The measurements from the TLS data showed strong correlations to field measurements. The study indicated that a suitable point density of the TLS data is a factor to consider for evaluating the different crown architectures of horticultural tree crops as the size of the TLS can significantly affect the data collection time and data processing efficiency. Hadas et al. (2019) used UAV-based LiDAR system following the 3D point cloud processing method described by Hadas et al. (2017) for the detection of local minima in crown profiles to successfully identify $99 \%$ of 655 apple trees and then selected 50 trees for mapping the crown structure, including crown area, tree height, and crown base height. The results showed that UAV-LiDAR data provided good accuracy for tree height and crown base height measurement compared with field data $(\mathrm{RMSE}=0.09 \mathrm{~m})$. However, UAV measurement reliability was a concern, and the researchers suggested several independent UAV flight experiments to reproduce the results. They also reported that validation of the results for 
other varieties of tree species, the impact of point cloud density, and the impact of flight altitude on the accuracy of the estimated traits need to be further investigated.

\section{Comparison of SfM and ToF Approaches}

Mlambo et al. (2017) constructed CHM with the SfM process on forest tree data from an UAV with an RGB camera to compare the tree height data from the ALS technique. Strong correlations between the SfM and ALS generated $\mathrm{DSM}$, and CHM $\left(\mathrm{R}^{2}=0.89\right.$ and 0.75 , respectively) were found. The SfM from the UAV data performed poorly in closed canopies as the algorithm could not generate sufficient below-canopy ground points. However, the study showed that the UAV imagery-based SfM for 3D modeling was a cost-effective option to substitute the ALS technique for plot-level measurements and replace traditional groundbased forest tree height measurement.

Wallace et al. (2016) compared the tools for 3D generation between the ALS and SfM techniques from UAV imagery at the plot level of a dry sclerophyll eucalypt forest. Individual tree traits were assessed from the two dense point cloud models that described the terrain surface and canopy properties of relatively low canopy closure. The study demonstrated that the tree height from the ALS data had higher accuracy compared with field-measured tree height (RMSE of $0.92 \mathrm{~m}$ for ALS data and $1.30 \mathrm{~m}$ for SfM data) because ALS could better penetrate the upper canopy to capture the vertical distribution of vegetation. In comparison, the SfM technique had lower accuracy when estimating height for densely populated tree canopies. However, the researchers still recommended SfM as a low-cost alternative for monitoring forest trees. Cao et al. (2019) applied two techniques for point cloud generation to develop 3D models using UAV-LiDAR data and UAV-RGB data, applying the SfM technique in a subtropical planted forest among different conditions (a range of tree species, height, and stem density). The accuracies for both 3D tree structures were comparable to the field measurements. The results showed a higher similarity between the LiDAR and SfM methods that appeared in the plots with greater height and lower stem density.

Hobart et al. (2020) used an UAV with an RGB camera to assess apple tree wall height. The point clouds were generated from a specific flight pattern $(10 \mathrm{~m}$ flight altitude, $1 \mathrm{~m} \mathrm{~s}^{-1}$ flight speed, and a flight path that followed the tree rows), camera perspective ( $20^{\circ}$ angle against nadir), and a 3D model was constructed with the SfM method. Comparison of the height data extracted from the UAV data and reference LiDAR point clouds for two seasons showed that low-altitude UAV imagery was suitable to evaluate apple tree wall growth (RMSE of $0.18 \mathrm{~m}$ for 2018 and $0.24 \mathrm{~m}$ for 2019). The study showed that the SfM method slightly underestimated the measurements, and the study recommended a higher forward overlap to generate point clouds of the whole tree to address this issue.

UAV imagery integrated with SfM photogrammetry has become a competitive alternative to LiDAR systems for generating 3D data due to its low cost, rapid data acquisition, and automated data processing (Iglhaut et al., 2019). In the above studies, the SfM technique provides nearly the same estimation accuracy of tree height in forest stands with reasonable error (although higher). Nevertheless, the studies showed that SfM did not provide the same gap penetration through tree canopies as LiDAR systems (Wallace et al., 2016; Mlambo et al., 2017; Cao et al., 2019; Moe et al., 2020). Considering the evaluation of tree height and tree architecture traits for thinning or pruning practices, SfM can be implemented before these activities and then used as baseline data for precise positioning for crop management. As the suitable period for the pruning is between late fall and early spring, which is the leaf-off season, the performances of SfM can be more accurate when there is less crown cover on the trees (Moudrý et al., 2019).

\section{SATELlite-BASEd Estimation}

Recently, there has been increased emphasis on another alternative to generate 3D data for the estimation of tree architecture traits over a large area. These studies have used high-resolution stereo imagery from satellite platforms such as Pléiades, WorldView 2 (WV-2), and WV-3. Persson and Perko (2016) demonstrated the application of an ALS system and stereo high-resolution WV-2 imagery (acquired as panchromatic along-track stereo pairs with a spatial resolution of $0.5 \mathrm{~m}$ ) to assess plot-level canopy height in a hemiboreal and boreal forest. For extraction of the tree height from the WV-2 images, a DSM was created from the WV-2 images using image-matching algorithms, and a DTM from ALS data was applied to derive the forest height. The study showed that the plot-level results had $6 \%$ to $10 \%$ RMSE when evaluated with field height measurement based on the Lorey technique and ALS data. Thus, for different test areas, forest conditions, and considering the lower RMSE, the researchers reported that stereo matching of WV-2 satellite images is suitable for forest height mapping. The spatial resolution showed the impact on canopy height accuracy when using stereo imagery, and the sparse forests tended to be underestimated.

Ullah et al. (2020) used three approaches to generate DSM (i.e., stereo aerial photography, stereo WV-2 using the image-matching, and radar satellite TanDEM-X data using interferometry) to calculate CHMs based on DTM from the ALS approach. The plot-level forest height was extracted from the CHMs, and the results showed that stereo aerial photography was the most accurate method, followed by WV-2 imagery and TanDEM-X data for estimating forest heights when compared with the field-based Lorey means and maximum heights. The researchers reported that the advantages of the active TanDEM-X sensor are its global availability and that images can be acquired day and night with no environmental constraint (i.e., not affected by cloud cover). Note that in the two studies discussed above, the accuracy of forest tree height estimation from high-resolution stereo satellite imagery relied on the accuracy of the DTM from the ALS technique.

Wu et al. (2020b) assessed 3D models of mango and avocado tree crowns to measure the height constructed from four of point cloud sources: TLS system, ALS system, WV-3 stereo imagery, and UAV-RGB and multispectral imagery-based SfM photogrammetry. The TLS data were con- 
sidered the most accurate dataset for the orchard environment, in which all the trees were short and sufficiently spaced so that the TLS system could cover the upper canopy and its apex. Therefore, the TLS dataset was applied as a reference for inter-comparison of the canopy heights measured with the other remote sensing platforms and field measurement data. The study found that UAV imagery had the highest accuracy and flexibility for estimating tree height, and this approach was suitable for collecting the tree height in an area of 1 to $10 \mathrm{~km}^{2}$. The WV-3 stereo imagery provided the lowest accuracy for both tree crops, implying that it was not suitable for mango (small tree, shorter than $5 \mathrm{~m}$ ), while moderate accuracy was achieved for mature avocado (larger and taller trees). Nonetheless, WV-3 was an option for largearea measurement of tree height for tall horticultural crops, considering its cost and commercial availability. High-resolution stereo imagery from satellite platforms is another useful resource that can potentially be used to extract tree height and other traits (Persson and Perko, 2016; Pearse et al., 2018; Wang et al., 2019; Wu et al., 2020b). Moreover, the reproducibility and affordability compared to field surveys and airborne campaigns provide flexibility to researchers using large areas of study.

\section{Crop Traits}

The major tree traits are briefly discussed below, including some additional traits that can represent architecture traits. Studies on tree height, canopy area, volume, and density are summarized in table 1 .

Table 1. Summary of the literature associated with canopy height and volume measurement. ${ }^{[\mathrm{a}]}$

\begin{tabular}{|c|c|c|c|c|c|c|}
\hline Trait & Tree Type & Purpose and Major Finding & $\begin{array}{c}\text { Data } \\
\text { Acquisition }\end{array}$ & $\begin{array}{c}\text { 3D Generating } \\
\text { Principle }\end{array}$ & $\begin{array}{c}\text { 3D } \\
\text { Modeling }\end{array}$ & Reference \\
\hline Canopy height & Forest & $\begin{array}{l}\text { Evaluated the performance of satellite stereo images. } \\
\text { Heights below the actual top height tended to have } \\
\text { unstable estimations. DTM from ALS was used to es- } \\
\text { timate height from the satellite images. }\end{array}$ & WorldView 2 & $\begin{array}{l}\text { Triangulation: } \\
\text { stereo vision }\end{array}$ & $\mathrm{CHM}$ & $\begin{array}{l}\text { Persson and } \\
\text { Perko, } 2016\end{array}$ \\
\hline Canopy volume & Almond & $\begin{array}{l}\text { Automated pipeline to estimate canopy volume, map- } \\
\text { ping flower and fruit distribution for yield prediction. } \\
\text { Fruit and flower classified using RGB images. }\end{array}$ & $\begin{array}{c}\text { 2D LiDAR / } \\
\text { mobile }\end{array}$ & Time of flight & Voxel grid & $\begin{array}{l}\text { Underwood } \\
\text { et al., } 2016\end{array}$ \\
\hline $\begin{array}{c}\text { Canopy volume } \\
\text { and height }\end{array}$ & Orange & $\begin{array}{l}\text { Developed the methods to estimate canopy volume } \\
\text { and tree height. Convex hull was suitable for trans- } \\
\text { versal sections of the tree row, and alpha shape was a } \\
\text { good option for individual trees. }\end{array}$ & $\begin{array}{c}\text { 2D LiDAR / } \\
\text { mobile }\end{array}$ & Time of flight & $\begin{array}{l}\text { Alpha shape, } \\
\text { convex hull }\end{array}$ & $\begin{array}{c}\text { Colaço et al., } \\
2017\end{array}$ \\
\hline $\begin{array}{l}\text { Canopy height } \\
\text { and other canopy } \\
\text { structures }\end{array}$ & Forest & $\begin{array}{l}\text { Developed the methods to extract canopy traits for } \\
\text { forest management. Local maxima combined with in- } \\
\text { verse watershed segmentation was used to estimate } \\
\text { crown diameters. }\end{array}$ & $\begin{array}{l}\text { RGB / } \\
\text { UAV }\end{array}$ & $\begin{array}{c}\text { Triangulation: } \\
\text { SfM }\end{array}$ & $\mathrm{CHM}$ & $\begin{array}{c}\text { Panagiotidis } \\
\text { et al., } 2017\end{array}$ \\
\hline $\begin{array}{l}\text { Canopy height } \\
\text { and other canopy } \\
\text { structures }\end{array}$ & Lychee & $\begin{array}{l}\text { Evaluated the responsiveness of pruning based on } \\
\text { tree traits. OBIA techniques were developed to ana- } \\
\text { lyze trees individually. UAV flight altitude influ- } \\
\text { enced the accuracy of canopy height. }\end{array}$ & $\begin{array}{c}\text { Multispectral / } \\
\text { UAV }\end{array}$ & $\begin{array}{c}\text { Triangulation: } \\
\text { SfM }\end{array}$ & $\mathrm{CHM}$ & $\begin{array}{c}\text { Johansen } \\
\text { et al., } 2018\end{array}$ \\
\hline Canopy volume & Olive & $\begin{array}{l}\text { Optimized the operating parameters of a harvester to } \\
\text { minimize tree and fruit damage. Two LiDAR systems } \\
\text { were applied in two laser scan orientations: upward } \\
\text { and sideways. Upward scanning provided a lower } \\
\text { canopy volume than lateral scanning. }\end{array}$ & $\begin{array}{l}\text { 2D LiDAR/ } \\
\text { mobile }\end{array}$ & Time of flight & $\begin{array}{l}\text { Alpha shape, } \\
\text { convex hull }\end{array}$ & $\begin{array}{l}\text { Pérez-Ruiz } \\
\text { et al., } 2018\end{array}$ \\
\hline $\begin{array}{c}\text { Canopy volume } \\
\text { and height }\end{array}$ & Almond & $\begin{array}{l}\text { Developed an automated method to construct a 3D } \\
\text { model for estimating canopy volume and height. } \\
\text { OBIA techniques were developed to analyze trees in- } \\
\text { dividually. }\end{array}$ & RGB / UAV & $\begin{array}{c}\text { Triangulation: } \\
\text { SfM }\end{array}$ & $\begin{array}{l}\text { DTM, DSM, } \\
\text { voxel grid }\end{array}$ & $\begin{array}{c}\text { Torres-Sánchez } \\
\text { et al., } 2018\end{array}$ \\
\hline Canopy volume & Grapevine & $\begin{array}{l}\text { Constructed the canopy map for site-specific ferti- } \\
\text { lizer application. Canopy volume was not statistically } \\
\text { different between the three methods. }\end{array}$ & $\begin{array}{c}\text { 2D LiDAR / } \\
\text { mobile, } \\
\text { RGB / UAV, } \\
\text { RGB-D / mobile }\end{array}$ & $\begin{array}{l}\text { Time of flight, } \\
\text { triangulation: } \\
\text { SfM, and } \\
\text { stereo vision } \\
\end{array}$ & $\begin{array}{c}\text { DSM, } \\
\text { voxel grid }\end{array}$ & $\begin{array}{c}\text { Andújar } \\
\text { et al., } 2019\end{array}$ \\
\hline $\begin{array}{c}\text { Canopy volume } \\
\text { and height }\end{array}$ & Olive & $\begin{array}{l}\text { Evaluated the detection of plant water stress for irri- } \\
\text { gation management. UAV flight altitude influenced } \\
\text { the accuracy of canopy height. }\end{array}$ & RGB / UAV & $\begin{array}{c}\text { Triangulation: } \\
\text { SfM }\end{array}$ & $\mathrm{CHM}$ & $\begin{array}{c}\text { Caruso et al., } \\
2019\end{array}$ \\
\hline $\begin{array}{c}\text { Canopy volume } \\
\text { and height }\end{array}$ & Grapevine & $\begin{array}{l}\text { Constructed the canopy mapping to analyze the irri- } \\
\text { gation effect. Voxel grid was suitable to estimate the } \\
\text { spaces in the canopy. }\end{array}$ & $\begin{array}{l}\text { 3D LiDAR / } \\
\text { mobile }\end{array}$ & Time of flight & $\begin{array}{l}\text { Convex hull, } \\
\text { voxel grid }\end{array}$ & $\begin{array}{l}\text { Chakraborty } \\
\text { et al., } 2019\end{array}$ \\
\hline $\begin{array}{c}\text { Canopy height } \\
\text { and other canopy } \\
\text { structures }\end{array}$ & Apple & $\begin{array}{l}\text { Evaluated the sensing method to estimate canopy } \\
\text { structures. A combination of principal component } \\
\text { analysis and local minima detection on crown pro- } \\
\text { files was used to analyze crown traits. }\end{array}$ & $\begin{array}{c}\text { 3D LiDAR / } \\
\text { UAV }\end{array}$ & Time of flight & Alpha shape & $\begin{array}{c}\text { Hadas et al., } \\
2019\end{array}$ \\
\hline $\begin{array}{c}\text { Canopy volume } \\
\text { and shape }\end{array}$ & Forest & $\begin{array}{l}\text { Developed the methods to evaluate } 3 \mathrm{D} \text { crown condi- } \\
\text { tions and analyzed the effect of the canopy on space } \\
\text { and light. Tree species and canopy conditions im- } \\
\text { pacted canopy space and aboveground competitive } \\
\text { neighborhood interactions. }\end{array}$ & TLS & Time of flight & Convex hull & $\begin{array}{c}\text { Krůček et al. } \\
2019\end{array}$ \\
\hline $\begin{array}{l}\text { Canopy volume } \\
\text { and bunch } \\
\text { detection }\end{array}$ & Grapevine & $\begin{array}{l}\text { Developed the automated methods for plant pheno- } \\
\text { typing. Vibration of the camera during data collection } \\
\text { affected data quality. Grape cluster recognition was } \\
\text { performed using convolutional neural networks. }\end{array}$ & RGB-D / mobile & $\begin{array}{l}\text { Triangulation: } \\
\text { stereo vision }\end{array}$ & $\begin{array}{l}\text { Convex hull, } \\
\text { voxel grid, } \\
\text { OBB, AABB }\end{array}$ & $\begin{array}{l}\text { Milella et al., } \\
2019\end{array}$ \\
\hline
\end{tabular}


Table 1 (continued). Summary of the literature associated with canopy height and volume measurement. ${ }^{[a]}$

\begin{tabular}{|c|c|c|c|c|c|c|}
\hline Trait & Tree Type & Purpose and Major Finding & $\begin{array}{c}\text { Data } \\
\text { Acquisition }\end{array}$ & $\begin{array}{c}\text { 3D Generating } \\
\text { Principle }\end{array}$ & $\begin{array}{c}\text { 3D } \\
\text { Modeling }\end{array}$ & Reference \\
\hline Canopy volume & Forest & $\begin{array}{l}\text { Evaluated the occlusion effect on canopy volume es- } \\
\text { timation. Estimation from above the canopy or the } \\
\text { ground should consider occlusion because it can lead } \\
\text { to biased results. }\end{array}$ & $\begin{array}{l}\text { TLS, } \\
\text { laser scanning / } \\
\text { UAV }\end{array}$ & Time of flight & Voxel grid & $\begin{array}{l}\text { Schneider } \\
\text { et al., } 2019\end{array}$ \\
\hline Canopy height & Forest & $\begin{array}{l}\text { Evaluated the performances of tree height estimation } \\
\text { techniques. ALS-based tree height estimation was the } \\
\text { most robust method for all standing trees. }\end{array}$ & ALS, TLS & Time of flight & $\mathrm{CHM}$ & $\begin{array}{c}\text { Wang et al., } \\
2019\end{array}$ \\
\hline Canopy volume & Forest & $\begin{array}{l}\text { Extracted canopy volume for use in forest manage- } \\
\text { ment. The concave hull provided acceptable canopy } \\
\text { volume compared to the other techniques. }\end{array}$ & $\begin{array}{c}\text { Laser scanning / } \\
\text { mobile }\end{array}$ & Time of flight & $\begin{array}{l}\text { Concave hull, } \\
\text { convex hull, } \\
\text { alpha shape, } \\
\text { voxel grid }\end{array}$ & $\begin{array}{c}\text { Yan et al., } \\
2019\end{array}$ \\
\hline Canopy volume & Grapevine & $\begin{array}{l}\text { Estimated the dry biomass and accuracy of branch } \\
\text { detection. The number of LiDAR scans influenced } \\
\text { the relationship with the actual biomass measure- } \\
\text { ment. }\end{array}$ & $\begin{array}{c}\text { 2D LiDAR / } \\
\text { mobile }\end{array}$ & Time of flight & Alpha shape & $\begin{array}{c}\text { Moreno et al., } \\
2020\end{array}$ \\
\hline $\begin{array}{l}\text { Canopy height } \\
\text { and fruit } \\
\text { detection }\end{array}$ & Apple & $\begin{array}{l}\text { Optimized the LiDAR-based measurement parame- } \\
\text { ters for fruit detection and yield prediction. Position } \\
\text { of the LiDAR and forced airflow status affected the } \\
\text { accuracy of fruit detection. Support vector machine } \\
\text { and } k \text {-means algorithms were used for fruit detection. }\end{array}$ & $\begin{array}{l}\text { 3D LiDAR / } \\
\text { mobile }\end{array}$ & Time of flight & $\begin{array}{c}\text { Boundary } \\
\text { box }\end{array}$ & $\begin{array}{l}\text { Gené-Mola } \\
\text { et al., } 2020\end{array}$ \\
\hline Canopy volume & Orange & $\begin{array}{l}\text { Explored Google Maps as an alternative for assessing } \\
\text { tree canopy volume. Google Maps could be used with } \\
\text { tree canopies larger than } 5 \mathrm{~m}^{3} \text {. }\end{array}$ & Google Maps & $\begin{array}{c}\text { Triangulation: } \\
\text { SfM }\end{array}$ & Convex hull & $\begin{array}{c}\text { Marín-Buzón } \\
\text { et al., } 2020\end{array}$ \\
\hline $\begin{array}{l}\text { Canopy volume } \\
\text { and height, } \\
\text { other canopy } \\
\text { structures }\end{array}$ & $\begin{array}{l}\text { Avocado, } \\
\text { macadamia, } \\
\text { mango }\end{array}$ & $\begin{array}{l}\text { Extracted the canopy volume to use in orchard man- } \\
\text { agement. TLS provided more details on individual } \\
\text { trees. ALS mainly relied on top-of-canopy infor- } \\
\text { mation. }\end{array}$ & ALS, TLS & Time of flight & $\begin{array}{c}\text { CHM, } \\
\text { voxel grid }\end{array}$ & $\begin{array}{c}\text { Wu et al., } \\
2020 \mathrm{a}\end{array}$ \\
\hline Canopy height & $\begin{array}{l}\text { Avocado, } \\
\text { mango }\end{array}$ & $\begin{array}{l}\text { Evaluated the performances of tree height estimation } \\
\text { techniques. TLS data were used as a reference to ana- } \\
\text { lyze the cost, spatial coverage, accuracy, and flexibil- } \\
\text { ity of acquiring data. }\end{array}$ & $\begin{array}{c}\text { ALS, TLS, } \\
\text { RGB / UAV } \\
\text { Multispectral / } \\
\text { UAV, } \\
\text { WorldView } 3 \\
\end{array}$ & $\begin{array}{l}\text { Time of flight, } \\
\text { triangulation: } \\
\text { SfM, and } \\
\text { stereo vision }\end{array}$ & $\mathrm{CHM}$ & $\begin{array}{c}\text { Wu et al., } \\
2020 \mathrm{~b}\end{array}$ \\
\hline $\begin{array}{l}\text { Tree row volume, } \\
\text { canopy volume, } \\
\text { leaf wall area, } \\
\text { canopy cover }\end{array}$ & $\begin{array}{c}\text { Grape, } \\
\text { apple }\end{array}$ & $\begin{array}{l}\text { Canopy architecture mapping for potential precision } \\
\text { spray application. Increasing the ground sampling } \\
\text { distance did not result in an increased relationship be- } \\
\text { tween ground measurements and aerial imagery data- } \\
\text { based estimates. }\end{array}$ & RGB / UAV & $\begin{array}{c}\text { Triangulation: } \\
\text { SfM }\end{array}$ & $\mathrm{CHM}$ & $\begin{array}{c}\text { Sinha et al., } \\
2021\end{array}$ \\
\hline
\end{tabular}

\section{TREe HEIGHT}

Tree height is a vital agronomic trait for assessing crop status and a vital selection parameter in breeding programs, especially in field conditions (Wiersma et al., 1986; Boukerrouand Rasmusson, 1990; Moles et al., 2009). Tree height estimation is also used as an indicator to estimate biomass (Persson and Fransson, 2017; Fernández-Sarría et al., 2019; Gennaro et al., 2020), yield (Sarron et al., 2018; López-Granados et al., 2019; Stateras and Kalivas, 2020), and health (Chang et al., 2020; Hobart et al., 2020; Jurado et al., 2020a, 2020b). In addition, canopy height from reconstructed 3D shape models is used to evaluate crop water status for irrigation planning. It can also be used as a guideline for sprayer settings to achieve a suitable spray volume and timing and as a variable to set the operation of harvesting machines and for pruning tasks in tree fruit orchards (Zhang et al., 2018; Aboutalebi et al., 2020; Pereira et al., 2020; Wu et al., 2020a, 2020b).

Traditionally, tree height is evaluated manually, which is laborious, time-consuming, and prone to error, considering the number of trees that need to be measured. Therefore, alternative but reliable and high-throughput methods for automating tree height measurement are needed for large-scale trials. Through the application of several platforms (such as satellite, UAV, autonomous ground vehicle) and sensing systems, including 3D computer vision, tree height can be extracted digitally.

\section{CANOPY AREa, Volume, AND DENSITY}

Canopy height estimation is useful for developing strategies to improve orchard and forest management. Other essential canopy traits that can be measured using 3D models include area, volume, and density. These traits can be directly associated with precision agriculture and assist in increasing crop management efficiency, such as pruning, harvesting, fertilizer and pesticide applications, and monitoring of breeding trials (Colaço et al., 2017; Patrick and Li, 2017; Torres-Sánchez et al., 2018; Caruso et al., 2019; Yan et al., 2019; Wu et al., 2020a; Zhu et al., 2020). Using the triangulation principle for generating point clouds, the stereo vision technique RGB-D has been used to measure canopy volume in tree fruits. Milella et al. (2019) applied these methods to estimate the volume of grapevine canopies, with major steps including 3D canopy modeling, segmentation of individual trees, and evaluation of the 3D models. Andújar et al. (2019) also used RGB-D, LiDAR mounted on a mobile platform, and RGB mounted on an UAV to measure grapevine volume and compare the three approaches' operating costs. The 
UAV-RGB system was found to be most cost-effective based on factors such as labor requirement, coverage area, data processing, and equipment.

Patrick and Li (2017) applied UAV imagery integrated with SfM to estimate the crown structure of highbush blueberry. High accuracy for canopy area estimation compared to manual measurement was found using the convex hull $\left(\mathrm{R}^{2}=0.83\right)$ and boundary rectangle $\left(\mathrm{R}^{2}=0.83\right)$ methods, and the convex hull was also used to calculate the canopy volume $\left(\mathrm{R}^{2}=0.954, \mathrm{RMSE}=0.063 \mathrm{~m}^{3}\right)$ by setting the shrink factor to zero. Other studies (Díaz-Varela et al., 2015; TorresSánchez et al., 2015; Jiménez-Brenes et al., 2017; Caruso et al., 2019) also used SfM to estimate canopy volume, area, height, and crown diameter. In general, the canopy height determined from the difference between DSM (some studies developed a reference surface model as DTM) and the canopy area determined from an individual object's pixel area was used to calculate the canopy volume (canopy area $x$ height). In addition, referring to the method from de Castro et al. (2019) described earlier, the DTM-based approach to segment the surface and the tree was used to calculate the canopy traits. Using the ToF approach to estimate the volume and area provides more accurate $3 \mathrm{D}$ point clouds for representing complex tree structures with high field variability. LiDAR mounted on a mobile platform or UAV was implemented to assess tree species such as almond, apple, grapevine, olive, orange, and forest species, and canopy volume was derived from the 3D models (Underwood et al., 2016; Colaço et al., 2017; Moreno et al., 2020; Pérez-Ruiz et al., 2018; Andújar et al., 2019; Chakraborty et al., 2019; Hadas et al., 2019; Gené-Mola et al., 2020). The primary processes for analyzing such datasets include $3 \mathrm{D}$ point cloud reconstruction, segmentation of individual tree or object-ofinterest point clouds, and 3D model construction. In general, the digital tree traits were calculated using methods such as convex hull, alpha shape, and voxel grid. The convex hull method can combine protruding branch tips to create the $3 \mathrm{D}$ model shape, while the voxel grid method cannot construct point clouds of trees without leaves (Zhu et al., 2020).

Many sensing technologies and processes have been used to produce $3 \mathrm{D}$ tree characterization to assess the tree canopy structure. However, the ground reference data used to validate these approaches is vital to ensure each method's accuracy and reliability. Because manual methods are challenging, Underwood et al. (2016) generated accurate LiDAR point clouds at different times (as ground reference data) in each season to validate the method. Similar approaches were used by Miranda-Fuentes et al. (2016) and Wu et al. (2020a, 2020b). Wu et al. (2020a) used TLS data as the ground reference to validate the ALS method during the estimation of individual horticultural tree canopy volume as the TLS data are perceived to be more efficient than ALS data for describing individual tree crowns (Jung et al., 2011). Tree canopy area and volume are essential structures for tree species management. Researchers are increasingly exploring new technologies and methods to estimate these traits, creating more competitive digital approaches. LiDAR can generally provide more dense point clouds by using a higher data acquisition frequency $(100 \mathrm{~Hz}$ or higher) than photogrammetry, providing a precise and concrete $3 \mathrm{D}$ model to estimate the complex tree structure. However, the most suitable estimation method depends on the tree canopy structure and the study objectives.

\section{OTher Traits}

In addition to the traits associated with canopy height, crown volume, crown area, and crown diameter, other traits can be evaluated, such as light interception (Sampson and Smith, 1993; Willaume et al., 2004; Buler and Mika, 2009; Tang et al., 2019; de Mattos et al., 2020; Anthony et al., 2020) and fractal dimension (Zhang et al., 2011, 2021; Guzmán et al., 2020), using sensing techniques as an indirect measurement of the canopy architecture. Many studies have reported the application of sensing systems for measuring light interception using sensing and analysis methods similar to those described above.

Stephan et al. (2008) evaluated the effects of two training systems (central leader and centrifugal) on canopy structure and light interception in three apple cultivars. The 3D reconstruction of trees (using the voxel grid method with $0.2 \mathrm{~m}$ voxels) was used to calculate the total leaf area and crown volume (using a bounding box across the canopy), which was then used to compute the mean leaf area density (total leaf area divided by crown volume). The silhouette to total area ratio (STAR) was also computed by dividing the projected leaf area by the total leaf area, which was considered a representation of light interception related to mean leaf irradiance relative to incident radiation. The researchers reported that, although there were no canopy-level differences between training systems, the centrifugal training had higher STAR values than the central leader at shoot level. The researchers also observed that vegetation shoots had higher STAR values than fruiting shoots in both training systems. Similarly, Giuliani et al. (2000) developed a system to integrate a light scanner (300 to $1100 \mathrm{~nm}$ solar radiation) for measuring light interception and side image of a peach tree canopy to calculate geometric traits (shape, size, etc.) to monitor the light shadow windows of the tree.

Lee et al. (2009) used 3D point cloud data from an ALS system to predict the in situ measured photosynthetically active part of intercepted solar radiation (IPAR), as measured using a quantum PAR sensor and an integrating PAR ceptometer. The differences in canopy structure of the two pine species were introduced based on type (loblolly and slash pine), vegetation control (none and sustained), and fertilization (none and nutrient supplementation). In general, good agreement was achieved between estimated and measured IPAR $\left(\mathrm{R}^{2}>0.91\right)$. The researchers noted that knowledge of site latitude and longitude along with the sun's position on specific dates and times with clear sky are important factors influencing the accuracy of the measurements. A similar comparison between simulated LiDAR data (TLS) and a voxel-based light interception model acquired from a physically-based ray-tracer in multiple forest tree species resulted in a mean absolute error of 5.78\% (Van der Zande et al., 2011).

Fractal analysis is another approach to measuring the degree of complexity in the tree architecture. Fractal dimension 
and lacunarity can serve as measures in morphological analysis (Alvarez et al., 2013) that account for gaps, inhomogeneity, textural variability, and other irregularities. Fractal analysis can be computed from 2D or 3D data. Zhang et al. (2011) used fractal analysis (2D data) to study two configurations of Fuji apple trees after pruning. Differences in fractal dimension numbers were found based on the tree age. Similarly, Zhang et al. (2021) evaluated the box-counting fractal dimension estimated from RGB images (2D data) of apple trees with three training systems and found a strong correlation $(r>0.74, p<0.05)$ with tree height and total fruit yield per unit area. LiDAR data (TLS and ALS) can also be used for estimating the fractal dimension.

Many of these studies focused on forest tree species (Seidel, 2018; Côté et al., 2018; Guzmán et al., 2020). For example, Seidel (2018) evaluated the box-counting fractal dimension estimated from LiDAR data to study the complexity of European ash, European beech, and Norway spruce species based on structural and architectural properties, in addition to its influence on competitive strength. Dorji et al. (2019) reported a strong correlation $(r=-0.78)$ between the box-counting fractal dimension estimated from a TLS system and the cumulative crown surface area, indicating the structural changes to competitive response in forest systems. Although such traits (e.g. fractal dimension) have been applied in the context of the forest system, they remain to be explored in the context of phenomics and precision agricultural applications. A thorough understanding of the relationship between such features and architectural traits is important to assess the suitability and application of such methods.

\section{Advancements and Practical CONSIDERATIONS}

Multiple sensing systems can be used for the $3 \mathrm{D}$ reconstruction of tree canopies and extracting canopy architecture traits. The selection of a specific sensing system and feature extraction method depends on several factors, such as cost of the sensor, desired accuracy, species of interest, growing conditions (individual trees, training systems, forest ecosystem, etc.), and the complexities associated with data processing and analysis. Both RGB-based SfM techniques and LiDAR-data based analysis have been successfully implemented to extract morphological features associated with crop performance (e.g., Wallace et al., 2016; Cao et al., 2019; Hobart et al., 2020). The accuracy in estimating architecture traits can also be associated with the sensor resolution, acquisition protocols, measurement range, and availability of ground reference data. For example, tree height is a relatively simple trait (although sometimes subjective), while factors such as canopy volume and density are hard to estimate manually as the acquisition of ground reference data can be challenging (Chakraborty et al., 2019). The accuracy of ground reference data defines the accuracy of the canopy trait estimation using sensor data. Nevertheless, the acquisition and analysis of remote sensing data can be the high-throughput process after protocols for data collection and analysis have been established.
One of the major benefits of using remote sensing for trait evaluation is its ability to assess temporal changes in the canopy structure. Although some studies (Underwood et al., 2016; Jiménez-Brenes et al., 2017; López-Granados et al., 2019) have assessed temporal changes within or across seasons in tree species, such assessments are still limited. López-Granados et al. (2019) extracted tree height, tree volume, flowering dynamics, and flowering density data from SfM-based point clouds and found that these factors showed a relationship with crown volume and yield in some almond species. Such temporal data across multiple seasons can be valuable for crop management and productivity, in addition to other applications such as predicting crop losses resulting from abiotic or biotic stress. The acquisition of 3D data from LiDAR systems during the season (multiple time points) integrated with laser return intensity (single or multiple wavelengths), also referred as 5-D data (Eitel et al., 2016), can also provide insights on the architecture traits of tree species. Some of the aspects highlighted by Eitel et al. (2016) associated with LiDAR data, such as large datasets and the absence of standardized data processing and analysis methods, remain challenging. With the more recent focus on developing data processing software for sensor applications in agriculture, such challenges may be addressed in the near future.

Regarding the SfM technique, major factors affecting 3D reconstruction include: (1) the region of interest (texture, pattern repetition, occlusions), (2) light conditions (sun angle, weather, stability of illumination), (3) camera specifications (focal length, exposure, aperture, shutter speed, pixel resolution, sensor size, field of view, depth of field), (4) imaging conditions (flight altitude, which is associated with GSD, imaging angle, image overlap), and (5) processing specifications (image resolution, ground control points) (Iglhaut et al., 2019). Another factor that needs to be considered is the canopy height with respect to the camera's depth of field. Decreasing the UAV flight altitude to increase the image resolution may not always lead to positive results because point matching may become more challenging (Iglhaut et al., 2019). Real-time kinematic (RTK) positioning of UAV may influence the measurement accuracy (Mulakala, 2019; Peppa et al., 2019; Ekaso et al., 2020; Urban et al., 2020), which may influence the accuracy of 3D reconstruction. Even though some studies have reported differences in measurement accuracy between LS systems and SfM-based data (e.g., Wallace et al., 2016; Cao et al., 2019; Hobart et al., 2020), the significance of these differences when evaluating the architecture traits of tree species and the ease of data collection need to be further considered.

In both agriculture and forestry, the similarity of the canopy may present challenges with point, feature, or object matching during the stitching (orthomosaic generation) process. Imaging with good contrast (e.g., tree fruit or tree with snow background in the absence of leaf cover to increase the contrast between soil and branch) and using ground control points can be useful in such cases (Zhang et al., 2021). Optimum environmental conditions (e.g., low wind, solar angle, solar intensity, etc.) are also critical factors that need to be considered.

Fractal analysis can be applied to the architectural complexity of tree species (Guzmán et al., 2020; Arseniou and 
MacFarlane, 2021), and it is important to understand such relationships. In a recent study, fractal geometry and tree metrics (height, crown area, volume, etc.) were generated from TLS point cloud data. The researchers found that the fractal dimension (voxel counting) and intercept could predict the variability of the tree metrics $\left(\mathrm{R}^{2}=0.61\right.$ to 0.98$)$, with the intercept showing stronger relationships with the total basal area, total covered area, and stand volume.

Future methods may involve applications of machine learning for data analytics involving architecture traits. Such applications include machine learning techniques for data fusion, such as multispectral, hyperspectral, and LiDAR data for better classification of tree species (Dalponte et al., 2012; Liao et al., 2018; Marrs and Ni-Meister, 2019), convolution neural network $(\mathrm{CNN})$ based extraction of architecture traits from video images (Itakura and Hosoi, 2018), and 3D CNN integrated LiDAR data for forest species monitoring (Ayrey and Hayes, 2018). Nevertheless, machine learning approaches may be more relevant for understanding the relationships between architecture traits and crop productivity than for the extraction of such traits, unless machine learning is used for the removal of noisy data or for the integration of data from multiple sources.

Other developments include using data from satellitebased synthetic-aperture radar (SAR) technology (Zhang et al., 2020), which is not affected by cloud cover, has high accuracy (e.g., spatial resolution as low as $0.25 \mathrm{~m}$ for TerraSAR-X), and can be used for measuring architecture traits (Ullah et al., 2020). In particular, the Global Ecosystem Dynamics Investigation (GEDI), involving high-resolution LiDAR sensing from the International Space Station (ISS), aims at monitoring Earth's forests and topology (Eegholm et al., 2019). More useful information on tree species can potentially be acquired from this source.

\section{ACKNOWLEDGEMENTS}

This work was supported in part by the Washington State University's Center for Sustaining Agriculture and Natural Resources BIOAg Program (project ID 184), the USDA National Institute of Food and Agriculture (NIFA) competitive project (Accession No. 1011741), and a USDA-NIFA hatch project (Accession No. 1014919).

\section{REFERENCES}

Aboutalebi, M., Torres-Rua, A. F., McKee, M., Kustas, W. P., Nieto, H., Alsina, M. M., ... Dokoozlian, N. (2020). Incorporation of unmanned aerial vehicle (UAV) point cloud products into remote sensing evapotranspiration models. Remote Sensing, 12(1), article 50. https://doi.org/10.3390/rs12010050

Alvarez, A. C., Passé-Coutrin, N., \& Gaspard, S. (2013). Determination of the textural characteristics of carbon samples using scanning electronic microscopy images: Comparison with mercury porosimetry data. Adsorption, 19(2), 841-850. https://doi.org/10.1007/s10450-013-9530-7

Andújar, D., Moreno, H., Bengochea-Guevara, J. M., de Castro, A., \& Ribeiro, A. (2019). Aerial imagery or on-ground detection? An economic analysis for vineyard crops. Comput. Electron. Agric., 157, 351-358.

https://doi.org/10.1016/j.compag.2019.01.007
Anthony, B., Serra, S., \& Musacchi, S. (2020). Optimization of light interception, leaf area, and yield in "WA38": Comparisons among training systems, rootstocks and pruning techniques. Agronomy, 10(5), article 689. https://doi.org/10.3390/agronomy10050689

Arseniou, G., \& MacFarlane, D. W. (2021). Fractal dimension of tree crowns explains species functional-trait responses to urban environments at different scales. Ecol. Appl., 31(4), e02297. https://doi.org/10.1002/eap.2297

Ayrey, E., \& Hayes, D. J. (2018). The use of three-dimensional convolutional neural networks to interpret LiDAR for forest inventory. Remote Sensing, 10(4), 649. https://doi.org/10.3390/rs10040649

Blaschke, T. (2010). Object-based image analysis for remote sensing. ISPRS J. Photogram. Remote Sens., 65(1), 2-16. https://doi.org/10.1016/j.isprsjprs.2009.06.004

Boukerrou, L., \& Rasmusson, D. D. (1990). Breeding for high biomass yield in spring barley. Crop Sci., 30(1), 31-35. https://doi.org/10.2135/cropsci1990.0011183X003000010007x

Buler, Z., \& Mika, A. (2009). The influence of canopy architecture on light interception and distribution in 'Sampion' apple trees. $J$. Fruit Ornamental Plant Res., 17(2), 45-52.

Büttgen, B., Oggier, T., Lehmann, M., Kaufmann, R., \& Lustenberger, F. (2005). CCD/CMOS lock-in pixel for range imaging: Challenges, limitations, and state-of-the-art. In $1 s t$ Range Imaging Research Day Proceedings (pp. 21-32). Zurich, Switzerland: ETH Zurich.

Camarretta, N., Harrison, P. A., Lucieer, A., Potts, B. M., Davidson, N., \& Hunt, M. (2020). From drones to phenotype: Using UAVLiDAR to detect species and provenance variation in tree productivity and structure. Remote Sensing, 12(19), article 3184. https://doi.org/10.3390/rs12193184

Campos, J., Llop, J., Gallart, M., García-Ruiz, F., Gras, A., Salcedo, R., \& Gil, E. (2019). Development of canopy vigour maps using UAV for site-specific management during vineyard spraying process. Prec. Agric., 20(6), 1136-1156. https://doi.org/10.1007/s11119-019-09643-Z

Cao, L., Liu, H., Fu, X., Zhang, Z., Shen, X., \& Ruan, H. (2019). Comparison of UAV LiDAR and digital aerial photogrammetry point clouds for estimating forest structural attributes in subtropical planted forests. Forests, 10(2), article 145. https://doi.org/10.3390/f10020145

Caruso, G., Guarino, F., Bianco, R. L., \& Marra, F. P. (2015). Yield and profitability of modified Spanish bush and Y-trellis training systems for peach. HortSci., 50(8), 1160-1164. https://doi.org/10.21273/hortsci.50.8.1160

Caruso, G., Tozzini, L., Rallo, G., Primicerio, J., Moriondo, M., Palai, G., \& Gucci, R. (2017). Estimating biophysical and geometrical parameters of grapevine canopies ('Sangiovese') by an unmanned aerial vehicle (UAV) and VIS-NIR cameras. Vitis, 56(2), 63-70.

Caruso, G., Zarco-Tejada, P. J., González-Dugo, V., Moriondo, M., Tozzini, L., Palai, G., ... Gucci, R. (2019). High-resolution imagery acquired from an unmanned platform to estimate biophysical and geometrical parameters of olive trees under different irrigation regimes. PLoS One, 14(1), e0210804. https://doi.org/10.1371/journal.pone.0210804

Chakraborty, M., Khot, L. R., Sankaran, S., \& Jacoby, P. W. (2019). Evaluation of mobile 3D light detection and ranging based canopy mapping system for tree fruit crops. Comput. Electron. Agric., 158, 284-293.

https://doi.org/10.1016/j.compag.2019.02.012

Chang, A., Yeom, J., Jung, J., \& Landivar, J. (2020). Comparison of canopy shape and vegetation indices of citrus trees derived from UAV multispectral images for characterization of citrus 
greening disease. Remote Sensing, 12(24), article 4122. https://doi.org/10.3390/rs12244122

Colaço, A. F., Trevisan, R. G., Molin, J. P., Rosell-Polo, J. R., \& Escola, A. (2017). A method to obtain orange crop geometry information using a mobile terrestrial laser scanner and 3D modeling. Remote Sensing, 9(8), article 763. https://doi.org/10.3390/rs9080763

Costes, E., Lauri, P. E., \& Regnard, J. L. (2006). Chapter 1: Analyzing fruit tree architecture: Implications for tree management and fruit production. In J. Janick (Ed.), Horticultural reviews (Vol. 32, pp. 1-61). https://doi.org/10.1002/9780470767986.ch1

Côté, J.-F., Fournier, R. A., Luther, J. E., \& van Lier, O. R. (2018). Fine-scale three-dimensional modeling of boreal forest plots to improve forest characterization with remote sensing. Remote Sens. Environ., 219, 99-114. https://doi.org/10.1016/j.rse.2018.09.026

Coupel-Ledru, A., Pallas, B., Delalande, M., Boudon, F., Carrié, E., Martinez, S., ... Costes, E. (2019). Multi-scale high-throughput phenotyping of apple architectural and functional traits in orchard reveals genotypic variability under contrasted watering regimes. Hortic. Res., 6(1), 52. https://doi.org/10.1038/s41438019-0137-3

Dalponte, M., Bruzzone, L., \& Gianelle, D. (2012). Tree species classification in the southern Alps based on the fusion of very high geometrical resolution multispectral/hyperspectral images and LiDAR data. Remote Sens. Environ., 123, 258-270. https://doi.org/10.1016/j.rse.2012.03.013

de Castro, A. I., Jimenez-Brenes, F. M., Torres-Sánchez, J., Peña, J. M., Borra-Serrano, I., \& López-Granados, F. (2018). 3-D characterization of vineyards using a novel UAV imagery-based OBIA procedure for precision viticulture applications. Remote Sensing, 10(4), article 584. https://doi.org/10.3390/rs10040584

de Castro, A. I., Rallo, P., Suárez, M. P., Torres-Sánchez, J., Casanova, L., Jiménez-Brenes, F. M., ... López-Granados, F. (2019). High-throughput system for the early quantification of major architectural traits in olive breeding trials using UAV images and OBIA techniques. Front. Plant Sci., 10, article 1472. https://doi.org/10.3389/fpls.2019.01472

de Mattos, E. M., Binkley, D., Campoe, O. C., Alvares, C. A., \& Stape, J. L. (2020). Variation in canopy structure, leaf area, light interception, and light use efficiency among Eucalyptus clones. Forest Ecol. Mgmt., 463, article 118038. https://doi.org/10.1016/j.foreco.2020.118038

Díaz-Varela, R. A., De la Rosa, R., León, L., \& Zarco-Tejada, P. J. (2015). High-resolution airborne UAV imagery to assess olive tree crown parameters using 3D photo reconstruction: Application in breeding trials. Remote Sensing, 7(4), 4213-4232. https://doi.org/10.3390/rs7040421

Dong, W., Roy, P., \& Isler, V. (2020). Semantic mapping for orchard environments by merging two-sides reconstructions of tree rows. J. Field Rob., 37(1), 97-121. https://doi.org/10.1002/rob.21876

Dorji, Y., Annighöfer, P., Ammer, C., \& Seidel, D. (2019). Response of beech (Fagus sylvatica L.) trees to competition: New insights from using fractal analysis. Remote Sensing, 11(22), article 2656. https://doi.org/10.3390/rs11222656

Eegholm, B., Wake, S., Denny, Z., Dogoda, P., Poulios, D., Coyle, B., ... Blair, B. (2019). Global Ecosystem Dynamics Investigation (GEDI) instrument alignment and test. Proc. SPIE, Vol. 11103, article 1110308. https://doi.org/10.1117/12.2532471

Eitel, J. U., Höfle, B., Vierling, L. A., Abellán, A., Asner, G. P., Deems, J. S., ... Vierling, K. T. (2016). Beyond 3-D: The new spectrum of LiDAR applications for earth and ecological sciences. Remote Sens. Environ., 186, 372-392. https://doi.org/10.1016/j.rse.2016.08.018
Ekaso, D., Nex, F., \& Kerle, N. (2020). Accuracy assessment of real-time kinematics (RTK) measurements on unmanned aerial vehicles (UAV) for direct geo-referencing. Geo-spatial Info. Sci., 23(2), 165-181. https://doi.org/10.1080/10095020.2019.1710437

Estornell, J., Velázquez-Martí, A., Fernández-Sarría, A., LópezCortés, I., Martí-Gavilá, J., \& Salazar, D. (2017). Estimation of structural attributes of walnut trees based on terrestrial laser scanning. Revista de Teledeteccion, 48, 67-76. https://doi.org/10.4995/raet.2017.7429

Fallati, L., Saponari, L., Savini, A., Marchese, F., Corselli, C., \& Galli, P. (2020). Multi-temporal UAV data and object-based image analysis (OBIA) for estimation of substrate changes in a post-bleaching scenario on a maldivian reef. Remote Sensing, 12(13), article 2093. https://doi.org/10.3390/rs12132093

Fazio, G., \& Robinson, T. (2008). Modification of nursery tree architecture with apple rootstocks: A breeding perspective. New York Fruit Qtly., 16(1), 13-16.

Fernández-Sarría, A., López-Cortés, I., Estornell, J., VelázquezMartí, B., \& Salazar, D. (2019). Estimating residual biomass of olive tree crops using terrestrial laser scanning. Intl. J. Appl. Earth Obs. Geoinfo., 75, 163-170. https://doi.org/10.1016/j.jag.2018.10.019

Garcerá, C., Fonte, A., Moltó, E., \& Chueca, P. (2017). Sustainable use of pesticide applications in citrus: A support tool for volume rate adjustment. Intl. J. Environ. Res. Public Health, 14(7), article 715. https://doi.org/10.3390/ijerph14070715

Gené-Mola, J., Gregorio, E., Auat Cheein, F., Guevara, J., Llorens, J., Sanz-Cortiella, R., ... Rosell-Polo, J. R. (2020). Fruit detection, yield prediction, and canopy geometric characterization using LiDAR with forced airflow. Comput. Electron. Agric., 168, article 105121. https://doi.org/10.1016/j.compag.2019.105121

Gennaro, S. F. D., Nati, C., Dainelli, R., Pastonchi, L., Berton, A., Toscano, P., \& Matese, A. (2020). An automatic UAV based segmentation approach for pruning biomass estimation in irregularly spaced chestnut orchards. Forests, 11(3), article 308. https://doi.org/10.3390/f11030308

Giuliani, R., Magnanini, E., Fragassa, C., \& Nerozzi, F. (2000). Ground monitoring the light-shadow windows of a tree canopy to yield canopy light interception and morphological traits. Plant Cell Environ., 23(8), 783-796. https://doi.org/10.1046/j.13653040.2000.00600.x

Gokavi, N., Mote, K., Jayakumar, M., Raghuramulu, Y., \& Surendran, U. (2021). The effect of modified pruning and planting systems on growth, yield, labour use efficiency, and economics of Arabica coffee. Scientia Horticulturae, 276, article 109764. https://doi.org/10.1016/j.scienta.2020.109764

Guzmán Q., Sharp, I., Alencastro, F., \& Sánchez-Azofeifa, G. A. (2020). On the relationship of fractal geometry and tree-stand metrics on point clouds derived from terrestrial laser scanning. Methods Ecol. Evol., 11(10), 1309-1318. https://doi.org/10.1111/2041-210X.13437

Hadas, E., Borkowski, A., Estornell, J., \& Tymkow, P. (2017). Automatic estimation of olive tree dendrometric parameters based on airborne laser scanning data using alpha-shape and principal component analysis. GISci. Remote Sensing, 54(6), 898-917. https://doi.org/10.1080/15481603.2017.1351148

Hadas, E., Jozkow, G., Walicka, A., \& Borkowski, A. (2019). Apple orchard inventory with a LiDAR equipped unmanned aerial system. Intl. J. Appl. Earth Obs. Geoinfo., 82, article 101911. https://doi.org/10.1016/j.jag.2019.101911

Hobart, M., Pflanz, M., Weltzien, C., \& Schirrmann, M. (2020). Growth height determination of tree walls for precise monitoring in apple fruit production using UAV photogrammetry. Remote 
Sensing, 12(10), article 1656. https://doi.org/10.3390/rs12101656

Hossain, M. D., \& Chen, D. (2019). Segmentation for object-based image analysis (OBIA): A review of algorithms and challenges from remote sensing perspective. ISPRS J. Photogrammetry Remote Sensing, 150, 115-134. https://doi.org/10.1016/j.isprsjprs.2019.02.009

Iglhaut, J., Cabo, C., Puliti, S., Piermattei, L., O’Connor, J., \& Rosette, J. (2019). Structure from motion photogrammetry in forestry: A review. Current Forestry Reports, 5(3), 155-168. https://doi.org/10.1007/s40725-019-00094-3

Itakura, K., \& Hosoi, F. (2018). Estimation of tree structure parameters from video frames with removal of blurred images using machine learning. J. Agric. Meteorol., 74(4), 154-161. https://doi.org/10.2480/agrmet.D-18-00003

Jiménez-Brenes, F. M., López-Granados, F., de Castro, A. I., Torres-Sánchez, J., Serrano, N., \& Peña, J. M. (2017). Quantifying pruning impacts on olive tree architecture and annual canopy growth by using UAV-based 3D modelling. Plant Methods, 13(1), article 55. https://doi.org/10.1186/s13007017-0205-3

Johansen, K., Raharjo, T., \& McCabe, M. F. (2018). Using multispectral UAV imagery to extract tree crop structural properties and assess pruning effects. Remote Sensing, 10(6), article 854. https://doi.org/10.3390/rs10060854

Jung, S.-E., Kwak, D.-A., Park, T., Lee, W.-K., \& Yoo, S. (2011). Estimating crown variables of individual trees using airborne and terrestrial laser scanners. Remote Sensing, 3(11), 2346-2363. https://doi.org/10.3390/rs3112346

Jurado, J. M., Ortega, L., Cubillas, J. J., \& Feito, F. R. (2020a). Multispectral mapping on 3D models and multi-temporal monitoring for individual characterization of olive trees. Remote Sensing, 12(7), article 1106. https://doi.org/10.3390/rs12071106

Jurado, J. M., Ramos, M. I., Enriquez, C., \& Feito, F. R. (2020b). The impact of canopy reflectance on the 3D structure of individual trees in a Mediterranean forest. Remote Sensing, 12(9), article 1430. https://doi.org/10.3390/rs12091430

Kenis, K., \& Keulemans, J. (2007). Study of tree architecture of apple (Malus $\times$ domestica Borkh.) by QTL analysis of growth traits. Molec. Breed., 19(3), 193-208. https://doi.org/10.1007/s11032-006-9022-5

Krause, S., Sanders, T. G., Mund, J.-P., \& Greve, K. (2019). UAVbased photogrammetric tree height measurement for intensive forest monitoring. Remote Sensing, 11(7), article 758. https://doi.org/10.3390/rs11070758

Krůček, M., Trochta, J., Cibulka, M., \& Král, K. (2019). Beyond the cones: How crown shape plasticity alters aboveground competition for space and light: Evidence from terrestrial laser scanning. Agric. Forest Meteorol., 264, 188-199. https://doi.org/10.1016/j.agrformet.2018.09.016

Lee, H., Slatton, K. C., Roth, B. E., \& Cropper, W. P. (2009). Prediction of forest canopy light interception using threedimensional airborne LiDAR data. Intl. J. Remote Sens., 30(1), 189-207. https://doi.org/10.1080/01431160802261171

Li, J., Yang, B., Cong, Y., Cao, L., Fu, X., \& Dong, Z. (2019). 3D forest mapping using a low-cost UAV laser scanning system: Investigation and comparison. Remote Sensing, 11(6), article 717. https://doi.org/10.3390/rs11060717

Liao, W., Van Coillie, F., Gao, L., Li, L., Zhang, B., \& Chanussot, J. (2018). Deep learning for fusion of APEX hyperspectral and full-waveform LiDAR remote sensing data for tree species mapping. IEEE Access, 6, 68716-68729. https://doi.org/10.1109/ACCESS.2018.2880083

López-Granados, F., Torres-Sánchez, J., Jiménez-Brenes, F. M., Arquero, O., Lovera, M., \& de Castro, A. I. (2019). An efficient RGB-UAV-based platform for field almond tree phenotyping: 3-
D architecture and flowering traits. Plant Methods, 15(1), article 160. https://doi.org/10.1186/s13007-019-0547-0

Marín-Buzón, C., Pérez-Romero, A., Tucci-Álvarez, F., \& Manzano-Agugliaro, F. (2020). Assessing the orange tree crown volumes using Google Maps as a low-cost photogrammetric alternative. Agronomy, 10(6), article 893. https://doi.org/10.3390/agronomy10060893

Marrs, J., \& Ni-Meister, W. (2019). Machine learning techniques for tree species classification using co-registered LiDAR and hyperspectral data. Remote Sensing, 11(7), article 819. https://doi.org/10.3390/rs11070819

Mesas-Carrascosa, F. J., de Castro, A. I., Torres-Sánchez, J., Triviño-Tarradas, P., Jiménez-Brenes, F. M., García-Ferrer, A., \& López-Granados, F. (2020). Classification of 3D point clouds using color vegetation indices for precision viticulture and digitizing applications. Remote Sensing, 12(2), article 317. https://doi.org/10.3390/rs12020317

Milella, A., Marani, R., Petitti, A., \& Reina, G. (2019). In-field high-throughput grapevine phenotyping with a consumer-grade depth camera. Comput. Electron. Agric., 156, 293-306. https://doi.org/10.1016/j.compag.2018.11.026

Miranda-Fuentes, A., Llorens, J., Rodriguez-Lizana, A., Cuenca, A., Gil, E., Blanco-Roldán, G. L., \& Gil-Ribes, J. A. (2016). Assessing the optimal liquid volume to be sprayed on isolated olive trees according to their canopy volumes. Sci. Total Environ., 568, 296-305.

https://doi.org/10.1016/j.scitotenv.2016.06.013

Mlambo, R., Woodhouse, I. H., Gerard, F., \& Anderson, K. (2017). Structure from motion (SfM) photogrammetry with drone data: A low-cost method for monitoring greenhouse gas emissions from forests in developing countries. Forests, 8(3), article 68. https://doi.org/10.3390/f8030068

Moe, K. T., Owari, T., Furuya, N., \& Hiroshima, T. (2020). Comparing individual tree height information derived from field surveys, LiDAR, and UAV-DAP for high-value timber species in northern Japan. Forests, 11(2), article 223. https://doi.org/10.3390/f11020223

Moles, A. T., Warton, D. I., Warman, L., Swenson, N. G., Laffan, S. W., Zanne, A. E., ... Leishman, M. R. (2009). Global patterns in plant height. $J$. Ecol., 97(5), 923-932. https://doi.org/10.1111/j.1365-2745.2009.01526.x

Moreno, H., Valero, C., Bengochea-Guevara, J. M., Ribeiro, Á., Garrido-Izard, M., \& Andujar, D. (2020). On-ground vineyard reconstruction using a LiDAR-based automated system. Sensors, 20(4), article 1102. https://doi.org/10.3390/s20041102

Moudrý, V., Gdulová, K., Fogl, M., Klápště, P., Urban, R., Komárek, J., ... Solský, M. (2019). Comparison of leaf-off and leaf-on combined UAV imagery and airborne LiDAR for assessment of a post-mining site terrain and vegetation structure: Prospects for monitoring hazards and restoration success. Appl. Geogr., 104, 32-41. https://doi.org/10.1016/j.apgeog.2019.02.002

Mulakala, J. (2019). Accuracy of the DJI Phantom 4 RTK using photogrammetry. DroneDeploy. Retrieved from https://www.dronedeploy.com/resources/ebooks/measurementaccuracy-dji-phantom-4-rtk-drone-photogrammetry/

Pádua, L., Marques, P., Hruška, J., Adão, T., Peres, E., Morais, R., \& Sousa, J. J. (2018). Multi-temporal vineyard monitoring through UAV-based RGB imagery. Remote Sensing, 10(12), article 1907. https://doi.org/10.3390/rs10121907

Panagiotidis, D., Abdollahnejad, A., Surový, P., \& Chiteculo, V. (2017). Determining tree height and crown diameter from highresolution UAV imagery. Intl. J. Remote Sens., 38(8-10), 23922410. https://doi.org/10.1080/01431161.2016.1264028

Patrick, A., \& Li, C. (2017). High-throughput phenotyping of blueberry bush morphological traits using unmanned aerial 
systems. Remote Sensing, 9(12), article 1250. https://doi.org/10.3390/rs9121250

Pearse, G. D., Dash, J. P., Persson, H. J., \& Watt, M. S. (2018). Comparison of high-density LiDAR and satellite photogrammetry for forest inventory. ISPRS J. Photogram. Remote Sensing, 142, 257-267. https://doi.org/10.1016/j.isprsjprs.2018.06.006

Peppa, M. V., Hall, J., Goodyear, J., \& Mills, J. P. (2019). Photogrammetric assessment and comparison of DJI Phantom 4 Pro and phantom 4 RTK small unmanned aircraft systems. ISPRS Archives (Vol. XLII-2/W13, pp. 503-509). https://doi.org/10.5194/isprs-archives-XLII-2-W13-503-2019

Pereira, L. S., Paredes, P., Melton, F., Johnson, L., Wang, T., López-Urrea, R., ... Allen, R. G. (2020). Prediction of crop coefficients from fraction of ground cover and height: Background and validation using ground and remote sensing data. Agric. Water Mgmt., 241, article 106197. https://doi.org/10.1016/j.agwat.2020.106197

Pérez-Ruiz, M., Rallo, P., Jiménez, M. R., Garrido-Izard, M., Suárez, M. P., Casanova, L., ... Morales-Sillero, A. (2018). Evaluation of over-the-row harvester damage in a super-highdensity olive orchard using on-board sensing techniques. Sensors, 18(4), article 1242. https://doi.org/10.3390/s18041242

Persson, H. J., \& Fransson, J. E. (2017). Comparison between TanDEM-X- and ALS-based estimation of aboveground biomass and tree height in boreal forests. Scandinavian J. Forest Res., 32(4), 306-319. https://doi.org/10.1080/02827581.2016.1220618

Persson, H. J., \& Perko, R. (2016). Assessment of boreal forest height from WorldView-2 satellite stereo images. Remote Sensing Letters, 7(12), 1150-1159. https://doi.org/10.1080/2150704X.2016.1219424

Poorter, L., Bongers, L., \& Bongers, F. (2006). Architecture of 54 moist-forest tree species: Traits, trade-offs, and functional groups. Ecology, 87(5), 1289-1301. https://doi.org/10.1890/00129658(2006)87[1289:AOMTST]2.0.CO;2

Rosell, J. R., \& Sanz, R. (2012). A review of methods and applications of the geometric characterization of tree crops in agricultural activities. Comput. Electron. Agric., 81, 124-141. https://doi.org/10.1016/j.compag.2011.09.007

Sampson, D. A., \& Smith, F. W. (1993). Influence of canopy architecture on light penetration in lodgepole pine (Pinus contorta var. latifolia) forests. Agric. Forest Meteorol., 64(1), 63-79. https://doi.org/10.1016/0168-1923(93)90094-X

Sarron, J., Malézieux, É., Sané, C. A. B., \& Faye, É. (2018). Mango yield mapping at the orchard scale based on tree structure and land cover assessed by UAV. Remote Sensing, 10(12), article 1900. https://doi.org/10.3390/rs10121900

Schneider, F. D., Kükenbrink, D., Schaepman, M. E., Schimel, D. S., \& Morsdorf, F. (2019). Quantifying 3D structure and occlusion in dense tropical and temperate forests using closerange LiDAR. Agric. Forest Meteorol., 268, 249-257. https://doi.org/10.1016/j.agrformet.2019.01.033

Schwarte, R., Heinol, H. G., Buxbaum, B., \& Ringbeck, T. (1999). Principles of three-dimensional imaging techniques. In Handbook of computer vision and applications: Sensors and imaging (Vol. 1, pp. 463-485). San Diego, CA: Academic Press.

Segura, V., Cilas, C., \& Costes, E. (2008). Dissecting apple tree architecture into genetic, ontogenetic, and environmental effects: Mixed linear modeling of repeated spatial and temporal measures. New Phytol., 178(2), 302-314. https://doi.org/10.1111/j.1469-8137.2007.02374.x

Segura, V., Durel, C.-E., \& Costes, E. (2009). Dissecting apple tree architecture into genetic, ontogenetic, and environmental effects:
QTL mapping. Tree Genetics Genomes, 5(1), 165-179. https://doi.org/10.1007/s11295-008-0181-x

Seidel, D. (2018). A holistic approach to determine tree structural complexity based on laser scanning data and fractal analysis. Ecol. Evol., 8(1), 128-134. https://doi.org/10.1002/ece3.3661

Sinha, R., Quirós, J. J., Sankaran, S., \& Khot, L. R. (2021). Highresolution aerial photogrammetry based $3 \mathrm{D}$ mapping of fruit crop canopies for precision inputs management. Info. Proc. Agric. (in press). https://doi.org/10.1016/j.inpa.2021.01.006

Stateras, D., \& Kalivas, D. (2020). Assessment of olive tree canopy characteristics and yield forecast model using high-resolution UAV imagery. Agriculture, 10(9), article 385. https://doi.org/10.3390/agriculture10090385

Stephan, J., Sinoquet, H., Donès, N., Haddad, N., Talhouk, S., \& Lauri, P.-E. (2008). Light interception and partitioning between shoots in apple cultivars influenced by training. Tree Physiol., 28(3), 331-342. https://doi.org/10.1093/treephys/28.3.331

Sterck, F. J., Bongers, F., \& Newbery, D. M. (2001). Tree architecture in a Bornean lowland rain forest: Intraspecific and interspecific patterns. Plant Ecol., 153(1), 279-292. https://doi.org/10.1023/A:1017507723365

Tang, L., Yin, D., Chen, C., Yu, D., \& Han, W. (2019). Optimal design of plant canopy based on light interception: A case study with loquat. Front. Plant Sci., 10, article 364. https://doi.org/10.3389/fpls.2019.00364

Torres-Sánchez, J., de Castro, A. I., Peña, J. M., Jiménez-Brenes, F. M., Arquero, O., Lovera, M., \& López-Granados, F. (2018). Mapping the 3D structure of almond trees using UAV acquired photogrammetric point clouds and object-based image analysis. Biosyst. Eng., 176, 172-184. https://doi.org/10.1016/j.biosystemseng.2018.10.018

Torres-Sánchez, J., López-Granados, F., Serrano, N., Arquero, O., \& Peña, J. (2015). High-throughput 3-D monitoring of agricultural-tree plantations with unmanned aerial vehicle (UAV) technology. PLoS One, 10(6), e0130479. https://doi.org/10.1371/journal.pone.0130479

Ullah, S., Dees, M., Datta, P., Adler, P., Saeed, T., Khan, M. S., \& Koch, B. (2020). Comparing the potential of stereo aerial photographs, stereo very high-resolution satellite images, and TanDEM-X for estimating forest height. Intl. J. Remote Sens., 41(18), 6976-6992. https://doi.org/10.1080/01431161.2020.1752414

Underwood, J. P., Hung, C., Whelan, B., \& Sukkarieh, S. (2016). Mapping almond orchard canopy volume, flowers, fruit, and yield using LiDAR and vision sensors. Comput. Electron. Agric., 130, 83-96. https://doi.org/10.1016/j.compag.2016.09.014

Urban, R., Reindl, T., \& Brouček, J. (2020). Testing of drone DJI Phantom 4 RTK accuracy. In Advances and trends in geodesy, cartography, and geoinformatics II. Boca Raton, FL: CRC Press. https://doi.org/10.1201/9780429327025-16

Van der Zande, D., Stuckens, J., Verstraeten, W. W., Mereu, S., Muys, B., \& Coppin, P. (2011). 3D modeling of light interception in heterogeneous forest canopies using groundbased LiDAR data. Intl. J. Appl. Earth Obs. Geoinfo., 13(5), 792-800. https://doi.org/10.1016/j.jag.2011.05.005

Vázquez-Arellano, M., Griepentrog, H. W., Reiser, D., \& Paraforos, D. S. (2016). 3-D imaging systems for agricultural applications: A review. Sensors, 16(5), article 618. https://doi.org/10.3390/s16050618

Wallace, L., Lucieer, A., Malenovský, Z., Turner, D., \& Vopěnka, P. (2016). Assessment of forest structure using two UAV techniques: A comparison of airborne laser scanning and structure from motion (SfM) point clouds. Forests, 7(3), article 62. https://doi.org/10.3390/f7030062 
Wang, J., Zhang, Y., \& Gu, R. (2020). Research status and prospects on plant canopy structure measurement using visual sensors based on three-dimensional reconstruction. Agric., 10(10), article 462. https://doi.org/10.3390/agriculture10100462

Wang, Y., Lehtomäki, M., Liang, X., Pyörälä, J., Kukko, A., Jaakkola, A., ... Hyyppä, J. (2019). Is field-measured tree height as reliable as believed: A comparison study of tree height estimates from field measurement, airborne laser scanning, and terrestrial laser scanning in a boreal forest. ISPRS J. Photogram. Remote Sens., 147, 132-145. https://doi.org/10.1016/j.isprsjprs.2018.11.008

Wiersma, D. W., Oplinger, E. S., \& Guy, S. O. (1986). Environment and cultivar effects on winter wheat response to ethephon plant growth regulator. Agron. J., 78(5), 761-764. https://doi.org/10.2134/agronj1986.00021962007800050002x

Willaume, M., Lauri, P.-É., \& Sinoquet, H. (2004). Light interception in apple trees influenced by canopy architecture manipulation. Trees, 18(6), 705-713. https://doi.org/10.1007/s00468-004-0357-4

Wu, D., Johansen, K., Phinn, S., \& Robson, A. (2020a). Suitability of airborne and terrestrial laser scanning for mapping tree crop structural metrics for improved orchard management. Remote Sensing, 12(10), article 1647. https://doi.org/10.3390/rs12101647

Wu, D., Johansen, K., Phinn, S., Robson, A., \& Tu, Y.-H. (2020b). Inter-comparison of remote sensing platforms for height estimation of mango and avocado tree crowns. Int. J. Appl. Earth Obs. Geoinf., 89, article 102091. https://doi.org/10.1016/j.jag.2020.102091
Wu, R. L. (1994). Quantitative genetics of yield breeding for Populus short-rotation culture: II. Genetic determination and expected selection response of tree geometry. Canadian $J$. Forest Res., 24(1), 155165. https://doi.org/10.1139/x94-021

Yan, Z., Liu, R., Cheng, L., Zhou, X., Ruan, X., \& Xiao, Y. (2019). A concave hull methodology for calculating the crown volume of individual trees based on vehicle-borne LiDAR data. Remote Sensing, 11(6), article 623. https://doi.org/10.3390/rs11060623

Zhang, C., Marzougui, A., \& Sankaran, S. (2020). High-resolution satellite imagery applications in crop phenotyping: An overview. Comput. Electron. Agric., 175, article 105584. https://doi.org/10.1016/j.compag.2020.105584

Zhang, C., Serra, S., Quirós-Vargas, J., Sangjan, W., Musacchi, S., $\&$ Sankaran, S. (2021). Non-invasive sensing techniques to phenotype multiple apple tree architectures. Info. Proc. Agric. (in press). https://doi.org/10.1016/j.inpa.2021.02.001

Zhang, S., Li, B., Liu, Y., Zhang, L., Wang, Z., \& Han, M. (2011). Fractal characteristics of two-dimensional images of 'Fuji' apple trees trained to two tree configurations after their winter pruning. Scientia Horticulturae, 130(1), 102108. https://doi.org/10.1016/j.scienta.2011.06.018

Zhang, Z., Wang, X., Lai, Q., \& Zhang, Z. (2018). Review of variable-rate sprayer applications based on real-time sensor technologies. In Automation in agriculture: Securing food supplies for future generations. https://doi.org/10.5772/intechopen.73622

Zhu, Z., Kleinn, C., \& Nölke, N. (2020). Assessing tree crown volume: A review. Forestry: Intl. J. Forest Res., 94(1), 18-35. https://doi.org/10.1093/forestry/cpaa037 